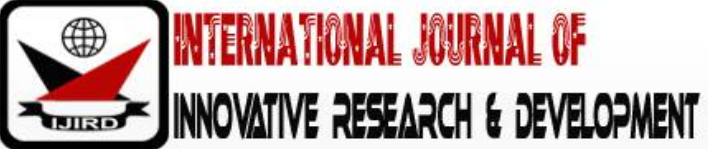

ISSN 2278 - 0211 (Online)

\section{Online Road Accident Victim Identification System in Nigeria}

\begin{tabular}{c} 
Iyawa, J.I.B \\
Chief Instructor, Department of Computer Education, \\
Federal College of Education (Technical), Nigeria \\
Binitie Amaka Patience \\
Lecturer, Department of Computer Science, \\
Federal College of Education (Technical), Nigeria \\
Festus-Amaka, E, N \\
Lecturer, Department of Cyber Security, \\
Federal University of Technology, Nigeria \\
\hline
\end{tabular}

\begin{abstract}
:
Road accident is an unexpected event that needs a prompt action to save victims lives. Developing countries like Nigeria, does not have a standardized method of identifying victims of accident in order to give immediate needed attention. This research work is aimed at developing an online identification system for easy and immediate identification of road accident victims in Nigeria, using finger print biometrics. Most often, unconscious accident victims die as a result of not receiving immediate and progressive medical attention which is caused by difficulty in identifying the victims. An online biometric identification system is designed and implemented. The methodology employed to model the system is Object Oriented Analysis and Design Methodology (OOADM). Visual Basic.NET is used to implement the system and Microsoft Structured Query Language database is used for the development of the database. The system will assist the law enforcement agencies and other organizations identify accident victims both in their conscious and unconscious state. Also, the system will use the global system for mobile communication technology to send short message to the victims' relative informing them of the accident and the victim's hospital location for quick response in order to save the lives of the victims.
\end{abstract}

Keywords: Road accident, biometrics, fingerprint, SMS, identification

\section{Introduction}

Road accident is an unexpected event that occurs as a result of operation of vehicles on roads and highways. In developing countries like Nigeria, road traffic accidents have contributed largely to loss of human lives and property (Agbonkhese, 2013). Though some known causes of road accidents include; over-speeding of drivers; making and receiving calls while driving; reckless driving; poor road management and maintenance, to mention but a few. The nonchalant attitudes of the emergency response team (ERT), when the victims arrive at the hospital, contributes majorly to the rate of human death. The consequent cause emanates from non-ease of victims' identification for immediate medical attention (Ojugo, et al., 2014).

Biometrics is referred to as an automated method of recognizing an individual based on a particular personal characteristic such as voice, face, fingerprint, hand geometry Deoxyribonucleic Acid (DNA), (Eslambolchi, 2013). Bowman (2000) noted that biometrics can be used in human recognition as forms of security in data processing activities to ensure data confidentiality and integrity.

In the recent past, the prevailing techniques for user authentication and identification had either involved the use of knowledge based (passwords) or token (identity cards, personal identification numbers) but all of these methods suffers from several limitations such as inaccurate, unreliable and costly to maintain. Presently, biometrics has gained importance in today's world where information security is essential. It has also been used to identify individual in groups that are under surveillance (Jain, et al. 2006). Personal identification of individual is based on some identifiers which are distinctive and measurable in nature. Due to uniqueness of these identifiers, thus, it cannot be stolen, lost, shared and forgotten. This has given the biometric system an edge over the traditional methodologies since it has the capability to be more accurate, convenient and cost effective.

\section{Review of Related Works}

Some research has been carried out which are related to the study. Some of the reviewed works include: Forensic Odontological observations on the victims of DANA air crash by Obafunwa, et al. (2015). The work was on identification of 
unknown human remains and bite mark using DNA analysis. The proposed system identifies road accident victims both in their conscious and unconscious state using fingerprint reader, connected and installed to the system.

Accident Detection System using heart beat sensor based mobile technology integrated with the evolving android smart phone by Kaladevi, et al. (2014). The paper presents heart beat sensor as a device used to measure the heat beat rate of an individual in order to detect an accident. When accident occurs, the system provides crucial information at the earliest possible time to the emergency responders who then respond to the scene of the accident and rescue victims thereby, reducing human death ratio in considerable amount. The proposed system uses short message service (SMS) to communicate to the victims' relative, informing them about the accident and victim's hospital location, thereby reducing the chances of victim abandonment and death rate.

\section{Methods}

The method adopted for the study was Object Oriented Analysis and Design Methodology. The methodology is best suited for the study as the system uses object technologies to create, manage and link the objects into useful computer application. It presents a systematic documentation of the various modules under the study and this enables the result of the study to be retrieved at ease.

\section{System Analysis}

\subsection{Analysis of the Existing System}

Presently in Nigeria, the system of alerting the necessary government officials in charge of road accident is done manually using phone calls. When accident occurs, the on lookers (passer-by) calls any of the emergency lines of the law enforcement agencies (e.g. dial 112 for Police) informing the officer in charge about the accident and its location. On reaching the accident scene, the officer assesses the fatality rate of the accident. If the accident is fatal, the officer invites the Hospital Emergency Response Team of the nearest government hospital in the town to move the bodies, but if ghastly, the officer is spurred to rush the victims to the hospital for medical attention.

Furthermore, the identification of accident victims is done through searching of the passengers' information in the manifest (hard copy) which most at times is unable to retrieve from the bus. At the hospital where the victims are brought to, the medical professionals in charge checks the state of these victims (conscious, unconscious or dead), if the victim is conscious, the victim is given first aid treatment but if unconscious, a test of life check is run on the victim to determine whether the victim is alive or dead. If the victim is alive, first aid treatment is administered but if confirmed dead, the victim is handed over to the coroner for autopsy to determine the actual cause of death. Then after, a thorough search is made on the victim's pocket for possible identification, if nothing is found, public announcement about the accident is made on air informing and urging the public whose relatives travelled on that route of the accident to come to the hospital for their ward's identification and claim. But if the victim(s) is not still identified after a period of time, the victim(s) would be buried en-mass.

\subsection{Weakness of the Existing System}

The existing system has the following weaknesses:

- Difficulty to identify unconscious accident victims: The unconscious accident victims were unable to identify as the victims has no identity proof such as identity card, ATM card, driver's license on them. This has increased the chances of victim's abandonment and unprogressive medical attention which endanger their lives.

- Inability to contact accident victims' relative:

- There is always a problem of identifying unconscious accident victim for life saving since no item of identity is found on the victim. Sometimes, the conscious accident victims' relative cannot be communicated on time due to the victim's condition which may not allow the provision of the relative active phone number, thus, delays the victim of not receiving appropriate medical attention.

- Difficulty I identifying dead accident victims can lead to the victim being buried en-mass.

- Irregularity of the passengers in filling the company's manifest:

- Passenger manifest is a document that contains the basic information about each passenger that boards a bus at the bus terminal. During bus loading, every passenger is required to fill the manifest but sometimes, some passenger ignore or feel less concern in filling the manifest. This constitutes a problem to bus company management as they could not give account of the passengers that boards the bus.

- Inability of the Law Enforcement Agents retrieving the passengers' manual manifest:

- This arises when there is much impact of the accident on the vehicle, thus retrieving passengers manifest on time become a challenge, thereby making it difficult to identify the victims.

\section{System Design}

A new system is proposed to help solve the problems posed by the existing system in identifying accident victims in Nigeria. The proposed system consists of two main modules; Transport module and Law enforcement module.

\subsection{Transport Module}

The module allows online registration of buses and passengers embarking on a journey with company transport bus. During passenger registration, the transport officer in charge captures the bus details, driver's details, and passenger's details for the passengers boarding the bus for the first time including the passenger's fingerprint, photo, and 
next of kin details. These details are further stored in the company's database which is linked to law enforcement agencies database for further operations. Figure 1 depicts the Transport module.

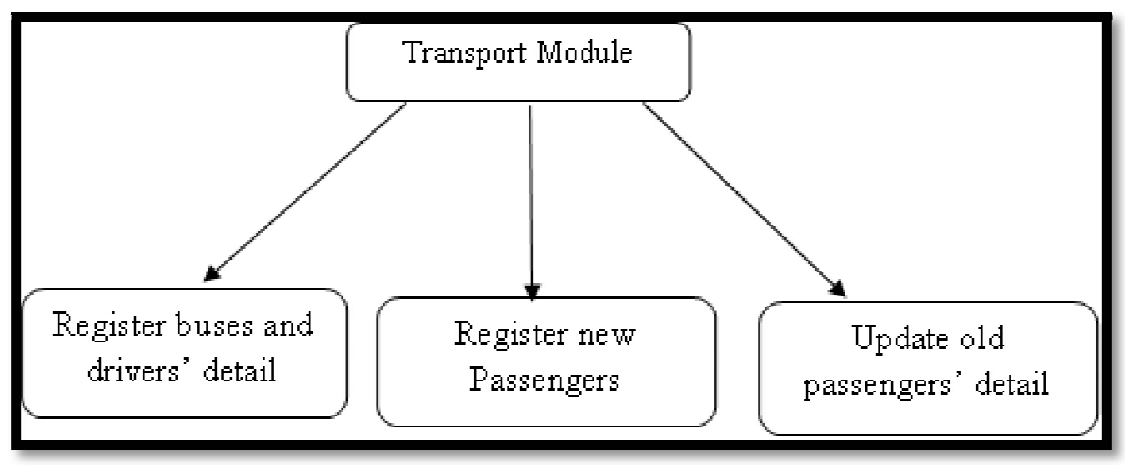

Figure 1: Transport Module

\subsection{Law Enforcement Agencies Module}

The module gives the law enforcement agent the privilege to view all the passengers' details from the system (computer). In the case of an accident, the agent reaching the scene of the accident will want to identify the unconscious victims. To achieve this, the law enforcement agent scans the victim's fingerprint using the fingerprint reader that is connected to the system. If the victim's fingerprint matches the fingerprint biometric template captured during registration at the bus terminal, the victim is identified by the system, then the officer compose text about the victim and the victim hospital location and send to the victim's relative else, the victim photo and details are posted to the social media (example, Facebook) for identification. Figure 2 depicts the Law enforcement agencies module.

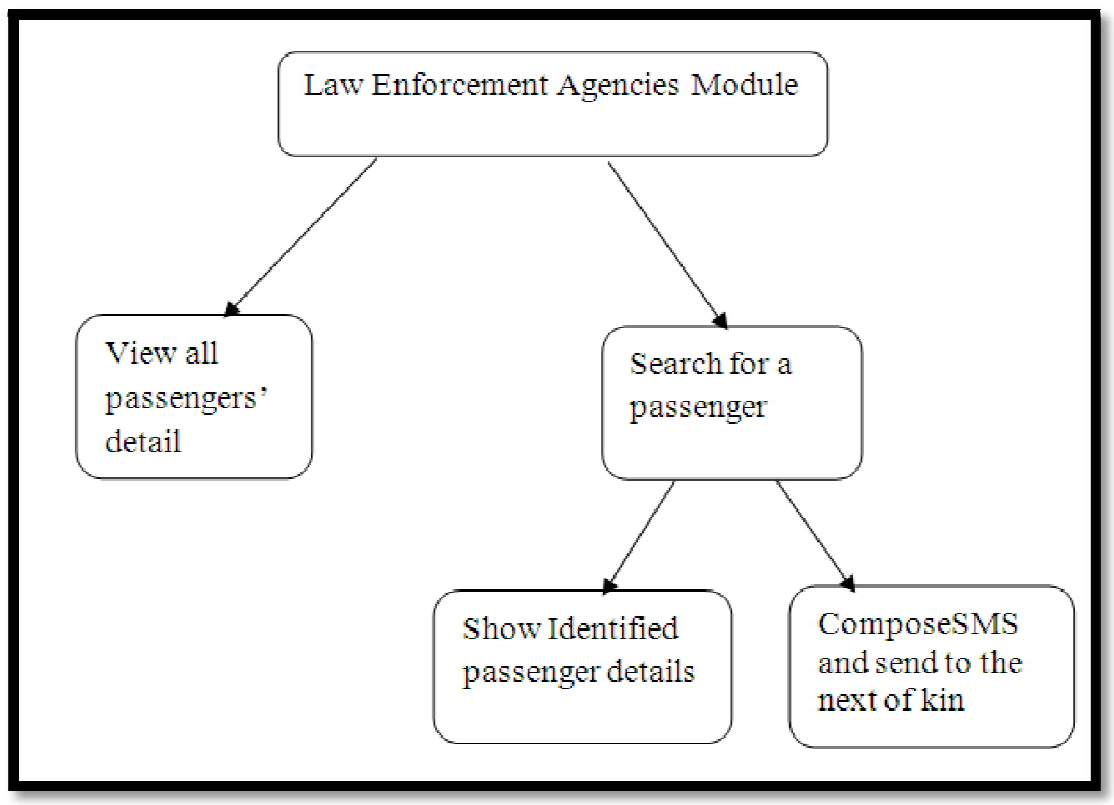

Figure 2: Law Enforcement Agencies Module

\subsection{Analysis of the Proposed System}

The proposed system "An Online Biometric System for Identification of Accident Victims is an improvement on passengers' identification using fingerprint biometrics method. The proposed system comprised of key actors: the transport officer and law enforcement officer (FRSC/ Police). Each of these actors has roles to play. With the system, every passenger is required to undergo a registration process. During the registration, the transport officer captures the bus details, passengers' details including their fingerprint, passport, next of kin name and contact phone number which is stored in the company's database linked to law enforcement agencies data base and is uploaded in the cloud.

In the case of an accident, the passers-by (onlookers) contact the law enforcement agent with their emergency lines (112 or 122) informing the officer of the accident and its location. On arriving at the scene of the accident, the officer in charge uses the system attached with the fingerprint reader to run identification on the victims. During the process, the system compares the new fingerprint supplied with the previously collected biometric template. If there is a match, the system identifies the victim and displays the victim's information. Then, the officer composes and sends short message service (SMS) to the identified victims' next of kin, notifying the relation of the victim hospital location. 


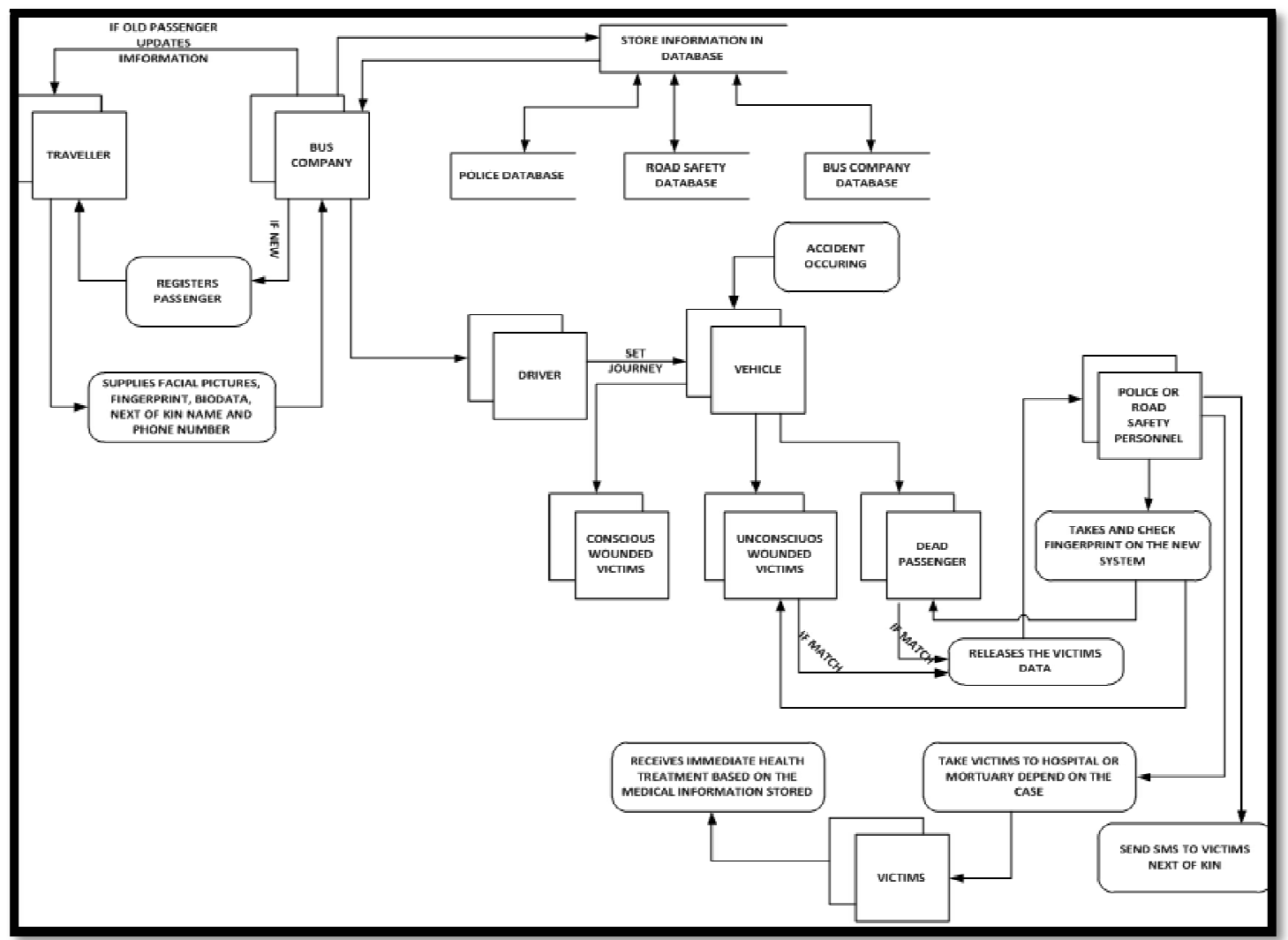

Figure 3: System Design

\section{System Implementation}

To design and manage the database, Microsoft Structured Query Language was used. This is because the storage engine provides more flexibility. During the implementation of the system, the required hardware and software tools were used and the system runs on Microsoft Visual Basic.NET. The system is implemented in parallel phase to enable the users get used to the proposed system before completely changeover.

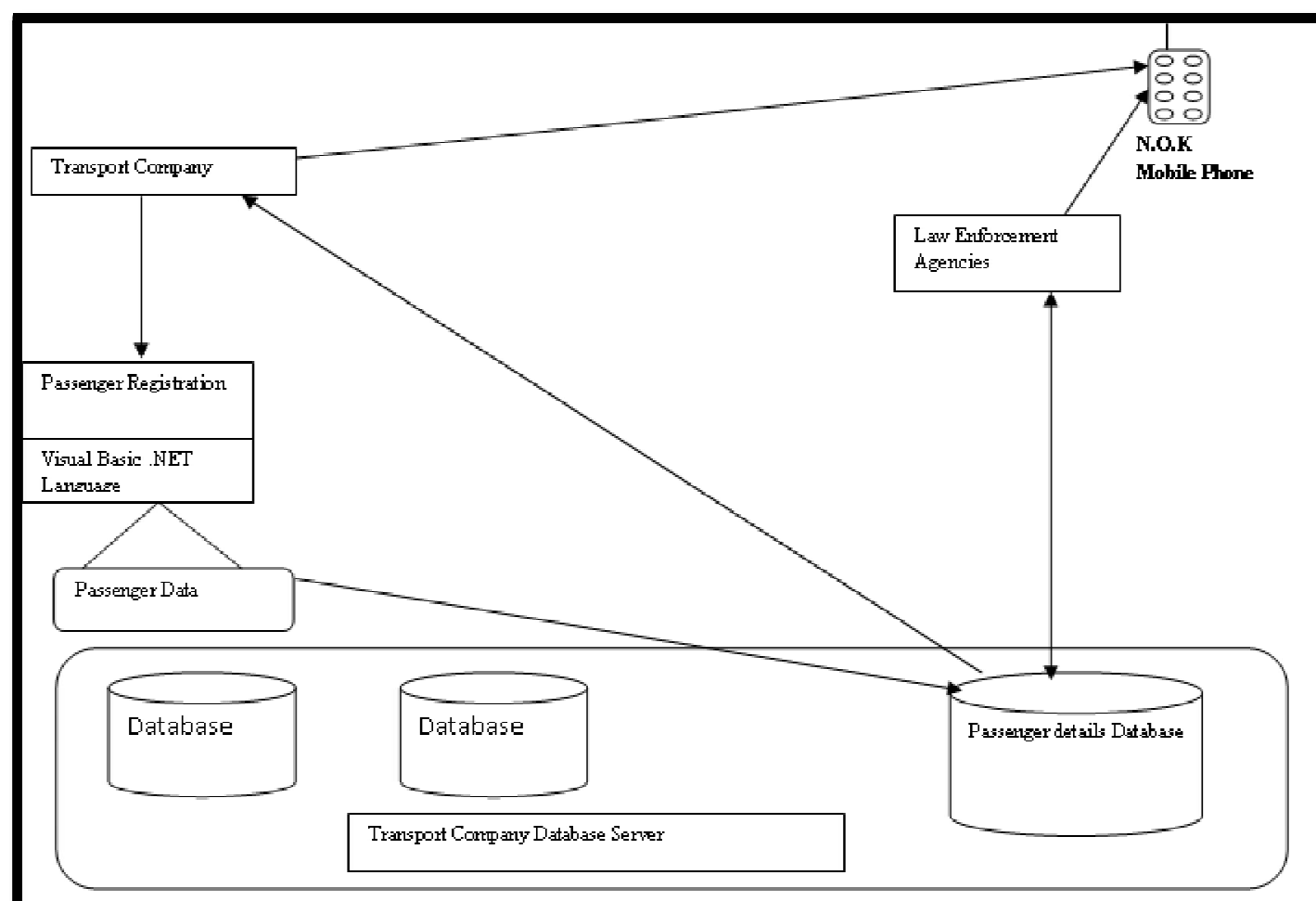

Figure 4: General System Prototype

Below are screen shoots of some modules' activities/ operations 


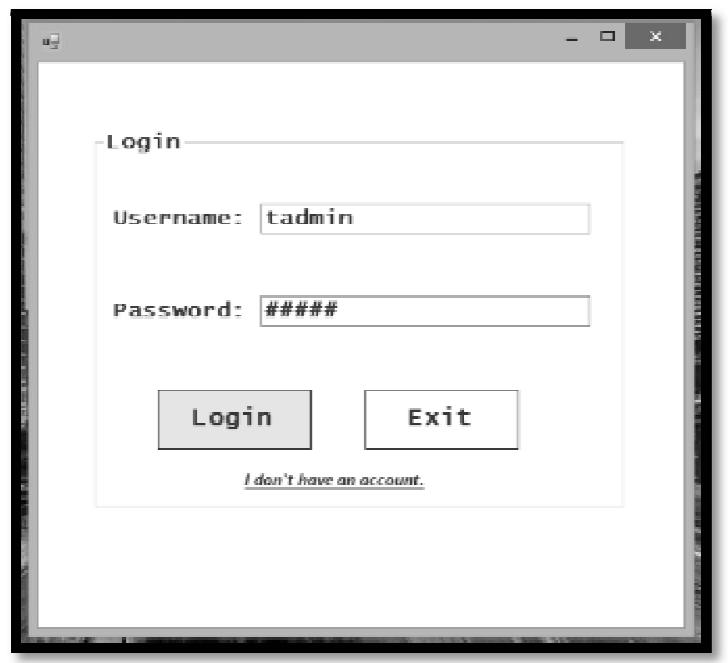

Figure 5 Login Page

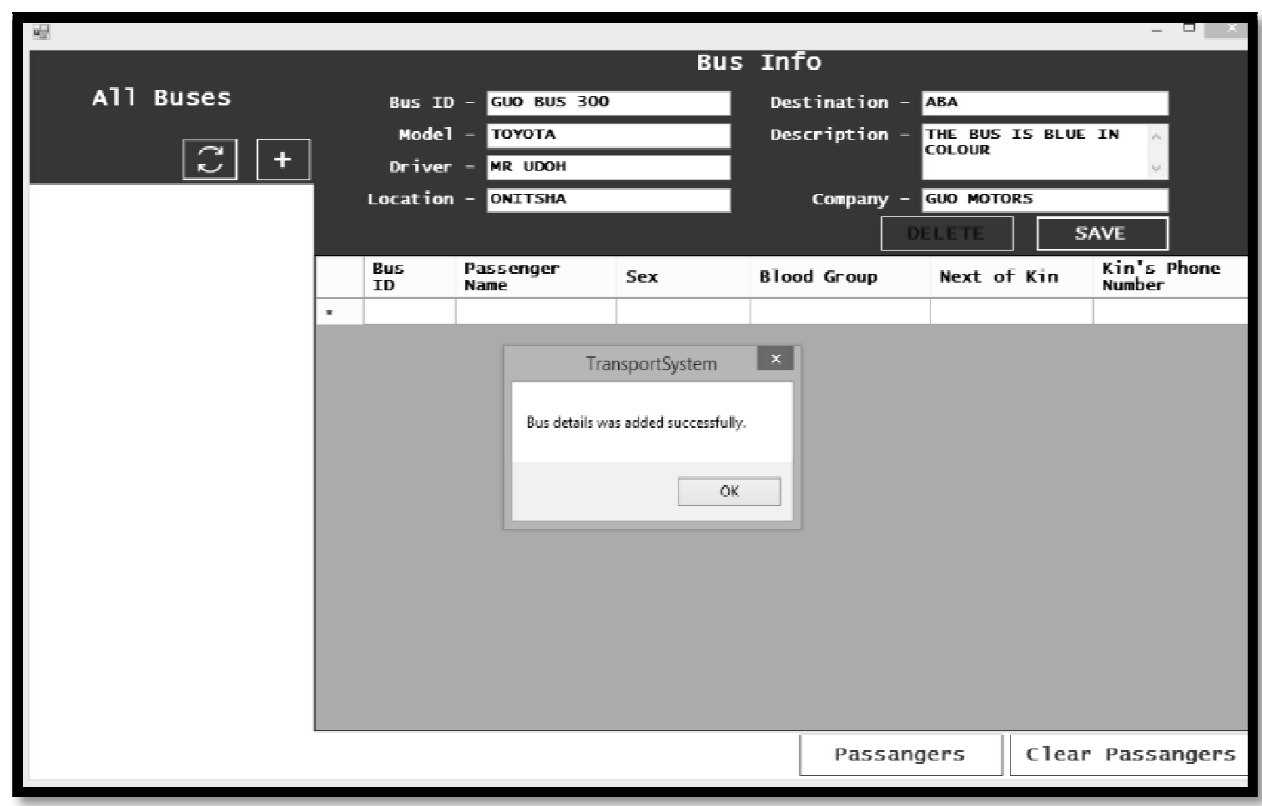

Figure 6: Bus and Driver Registration Page

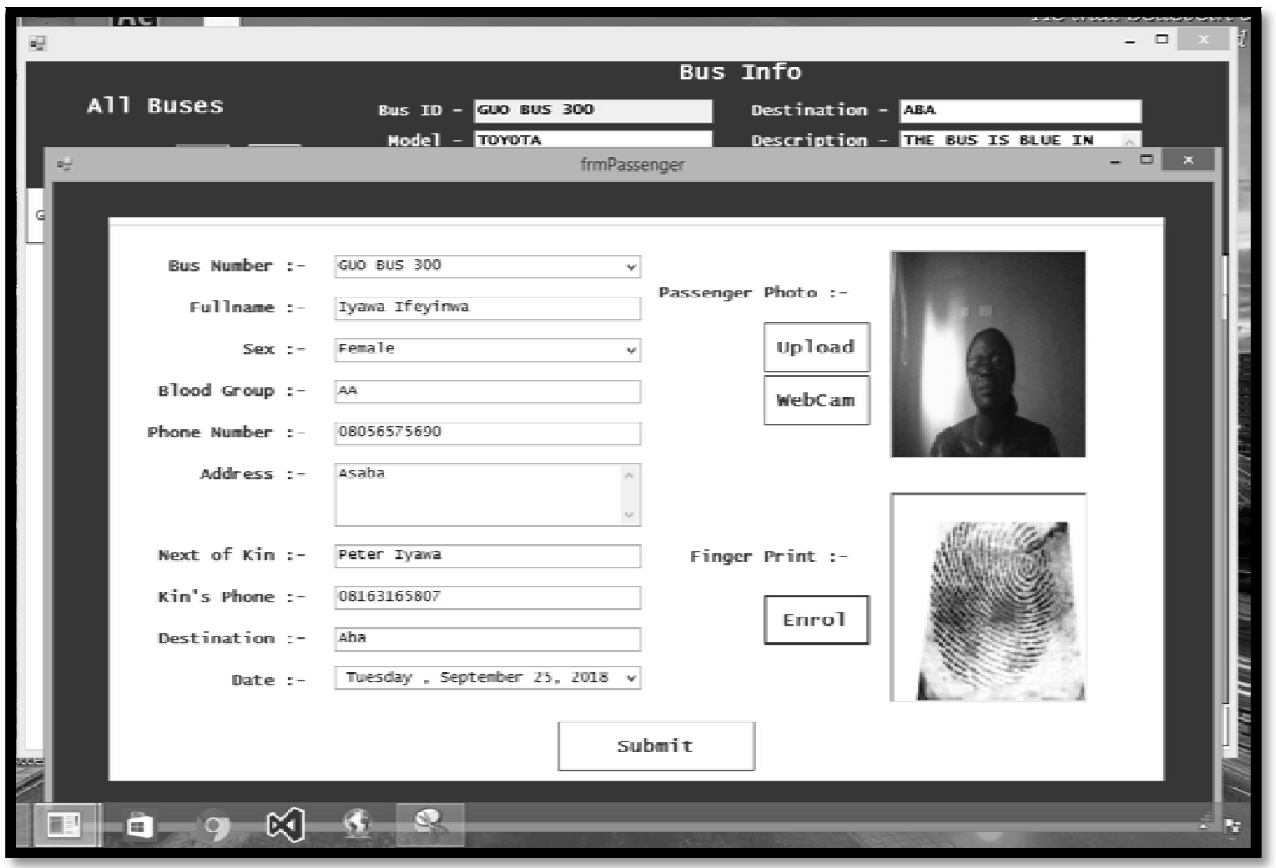

Figure 7: Completed Passenger Registration Page 


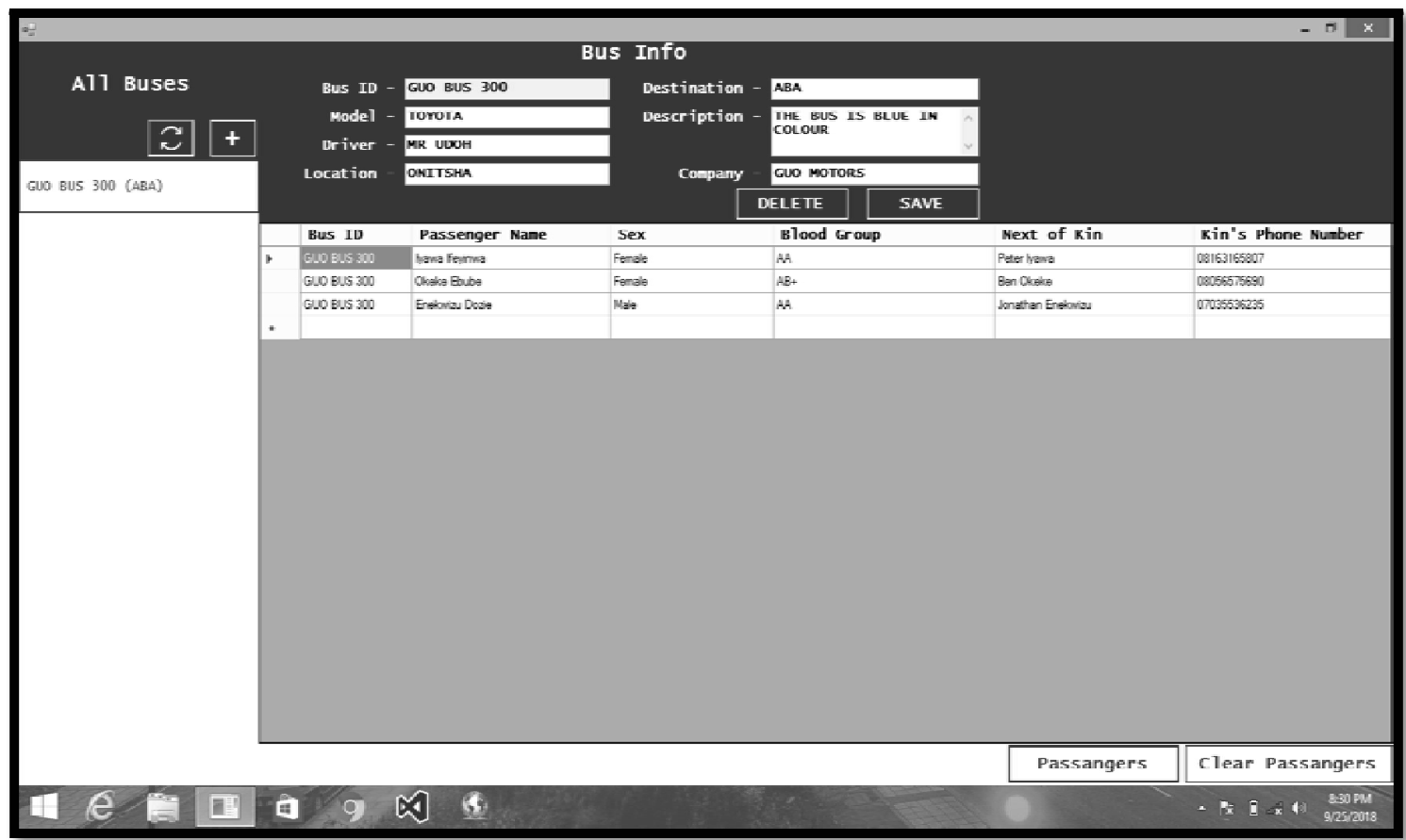

Figure 8: Registered Passengers' Details (Manifest) Page

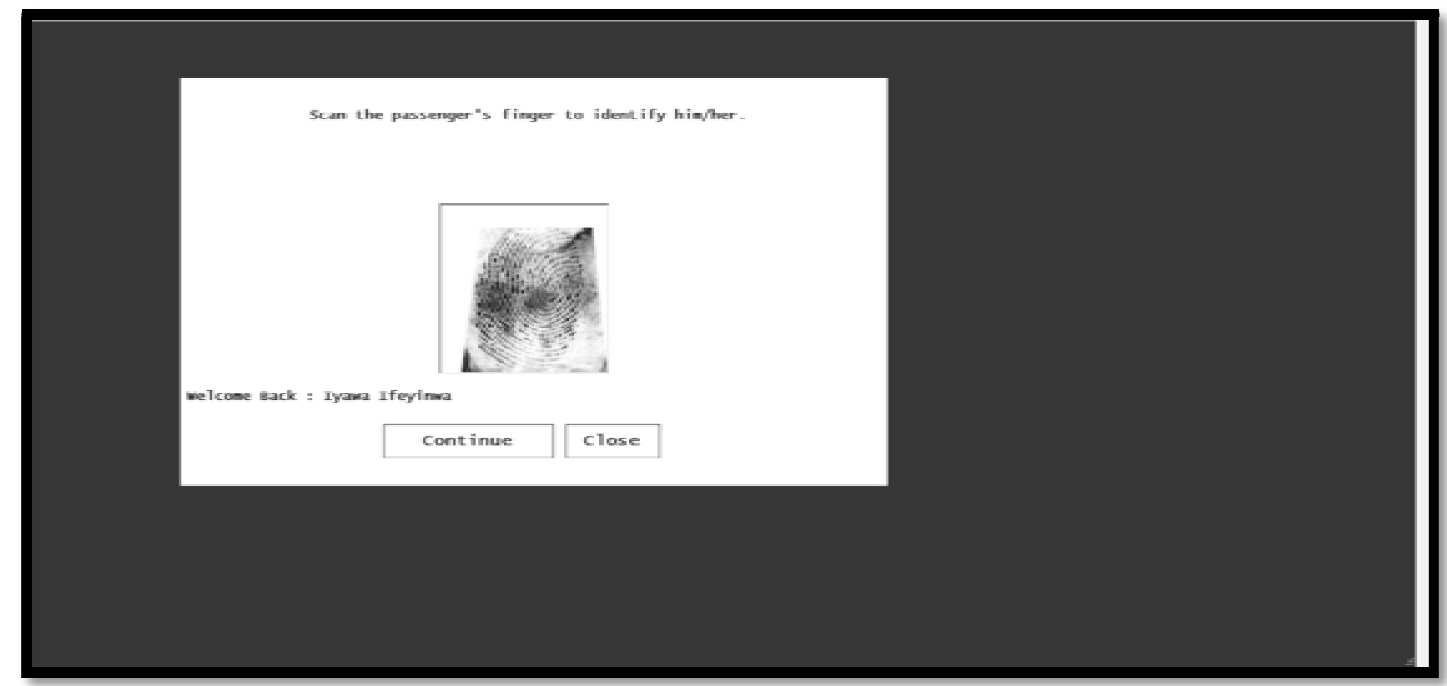

Figure 9: Verified Passenger's Fingerprint for Identification

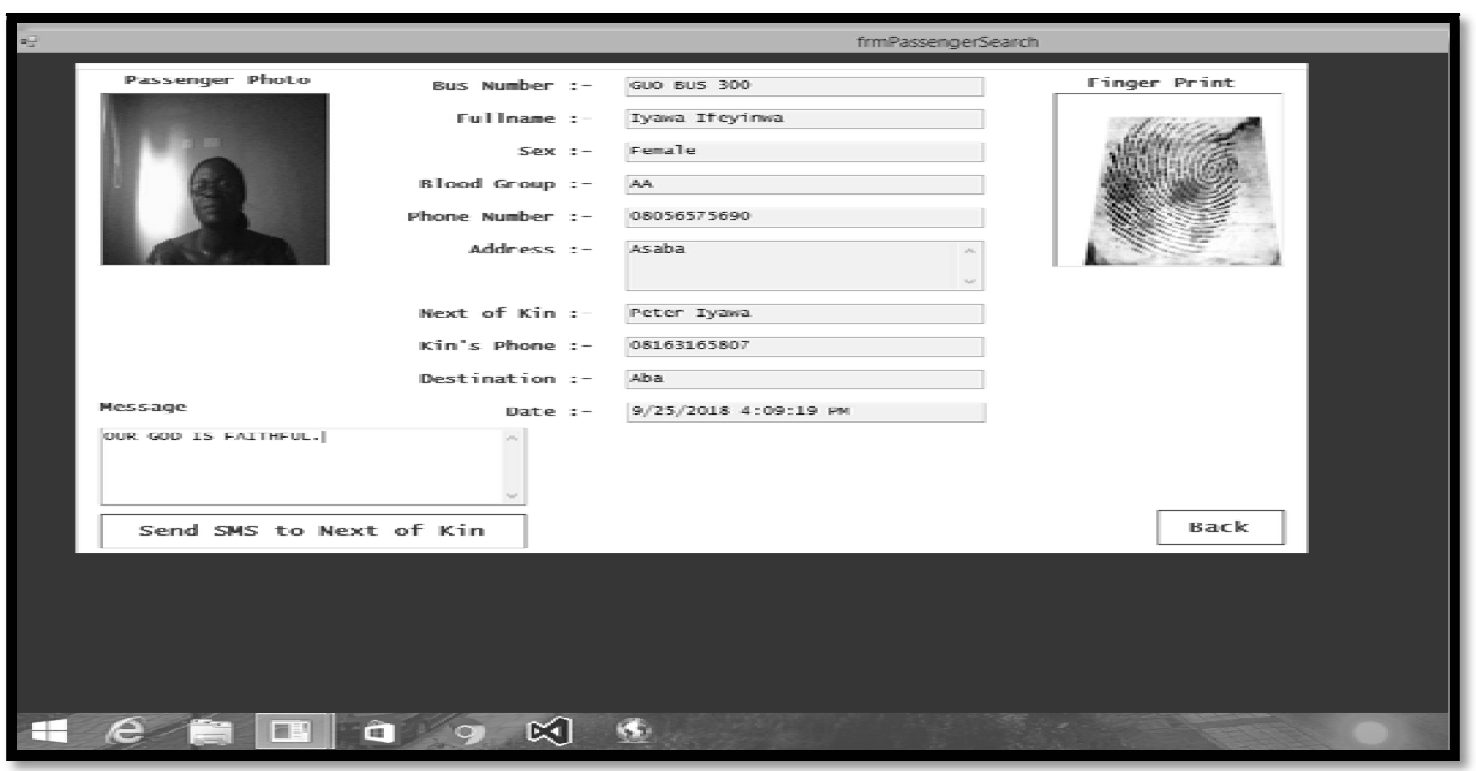

Figure 10: Identified Passenger(Victim) Details 


\section{Conclusion}

Conclusively, the fundamental right in every society of the world is "Right to Life", nobody is allowed to die unnecessarily. Meanwhile, road accidents have and are still claiming many lives in this nation due to difficulty in identifying accident victims for medical attention. The project has shown that easy identification of accident victims will curb the problems the victims encountered as a result of inability to communicate to their relations for immediate medical attention. This project if deployed will provide sufficient identification module to health institutions, Law enforcement agencies (FRSC and Police) and other organizations to enable them save lives within the critical time of victims' unconsciousness.

\section{Reference}

i. $\quad$ Agbonkhese, O., Yisa, G.L. Agbonkhese, E.G., Akanbi, D.O., Aka, E.O \& Mondigha, E.B (2013). Road Traffic Accidents in Nigeria: Causes and preventive measures. Civil and environmental research 3(10):90-99.

ii. Bowman, E. (2000)."Everything you need to know about biometrics” tech rep., Identix Corporation, retrieved from http:/ / www.ibia.org/ Everything About Biometrics.PDF, 2000.

iii. Eslambolchi, H. (2013). How biometrics will change 21st century communications. Retrieved from http:/ / www.linkedin.com on September 24, 2013.

iv. Federal Road Safety Corps Annual Report (2013). Road traffic accidents: the way forward www.frsc.gov.ng/ publications. Retrieved on July 2017.

v. Jain, A.K., Ross, A. \& Pankanti, S. (2006). Biometric: A tool for information Security. IEEE Transactions on Information Forensics and Security, 1 (2):125-143.

vi. Kaladevi, P., Kokila, T., Narmatha, S. \& Janani, V. (2014). Accident Detection using android smart phone. . International Journal of Innovation Research in Computer and Communication Engineering. 2(1):34-97.

vii. Obafunwa, J.O., Soyem, S.S., Ogunbanjo, V.O., Ogunbanjo, O.B. \& Faduyile, F.A. (2015). Forensic Odontological observations in the victim of DANA air crash. The Pan African Medical Journal. Retrieved from http:/ / www.panafrican-med-journal.com/ content/ article/ 20/ 96/ fullon July 2017.

viii. Ojugo, A.A., Yoro, R.E., Eboka, A.O \& Yerokun, M.O., (2014). Genetic algorithm trained neural network model for biometric identification scheme, ACIS: Automation, Control and Information Systems, 2(2): 71-75. 